\title{
THE FORMAL AND CONTEXTUAL RELATION OF TYPOGRAPHIC AND VISUAL ELEMENTS OF PJ HARVEY ALBUM COVERS
}

\author{
Cinla Seker ${ }^{*}$
}

\begin{abstract}
The aim of this research is to determine 21st century's formal and contextual design solutions with the guidance of graphic design principles by analyzing design products. Twenty-nine times nominated and six times winner for the international worldwide music awards Pj Harvey's eight alternative rock studio album covers have chosen; Dry (1992), Rid of Me (1993), To Bring You My Love (1995), Is this Desire?(1998), Stories from the City, Stories from the Sea (2000), Uh Huh Her (2004), White Chalk (2007), Let England Shake (2011).Graphic design as a design discipline in special means determining the formals of a $2 d$ before production process according to the context. Album covers are one of the many graphic design products of 21st century. With the help of an album cover the artist reflects an audial expression visually. For a successful visualization some graphic design principles should have been considered by the designers. Design principles are the guides of organizing elements like visuals, typography and color. In this research five design principles are looked for; unity/harmony, balance, hierarchy, scale/proportion, dominance/emphasis and, similarity and contrast. On Pj Harvey's album covers it is determined that every five of these principles were considered by the graphic designer during the design process as outlined.
\end{abstract}

INTRODUCTION........................................................................... 750

I. Album Covers as a Graphic DeSIGN Product................................... 751

A. Analysis of Pj Harvey Album Covers...................................... 752

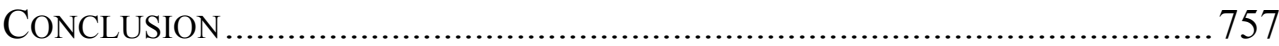

\section{INTRODUCTION}

Formal and functional features determination process called the design. It is made before the production process of a product. Like many production items printed $2 \mathrm{~d}$ materials that are one of a many design fields and it's called graphic design. With an extended meaning today graphic designer organizes the artistic elements under the consideration of design principles. In 2003 at the turning point of the millennium Lidwell, Holden and Butler stated universal principles of design in their interdisciplinary work on

\footnotetext{
*Assistant professor at the Fine Arts Education Department at the Dokuz Eylul University, Izmir, Turkey. Research fields: Graphic Design, Basic Design Theory, Visual Arts and İts Education.
} 


\section{THE FORMAL AND CONTEXTUAL RELATION 751}

design. ${ }^{1}$ Graphic design as a design discipline is determining the formals of a $2 \mathrm{~d}$ before production process according to the context. Album covers are one of the many graphic design products of 21st century. With the help of an album cover the artist reflects an audial expression visually. For a successful visualization some graphic design principles should have been considered by the designers. Design principles are the guides of organizing elements like visuals, typography and color .In this research six design principles are looked for; unity/harmony, balance, hierarchy, scale/proportion, dominance/emphasis and, similarity and contrast.

The aim of this research is to determine 21 st century's formal and contextual design solutions with the guidance of graphic design principles by analyzing design products. 1969 born Polly Jean Harvey is an English musician, singer-songwriter, composer, writer and poet. Twenty-nine times nominated and six times winner for the international worldwide music awards $\mathrm{Pj}$ Harvey's eight alternative rock studio album covers have chosen; Dry (1992), Rid of Me (1993), Is this Desire?(1998), Stories from the City, Stories from the Sea (2000), Uh Huh Her (2004), To Bring You My Love (2007), White Chalk (2007), Let England Shake (2011). Pj Harvey has received the 2001 and 2011Mercury Prize for Stories from the City, Stories from the Sea and Let England Shake respectively -the only artist to have been awarded the prize twice- eight BRIT Award nominations, six Grammy Award nominations and two further Mercury Prize nominations. Rolling Stone awarded her 1992's Best New Artist and Best Singer Songwriter and 1995's Artist of the Year, and listed Rid of Me, To Bring You My Love and Stories from the City, Stories from the Sea on its500 Greatest Albums of All Timelist. In 2011, she was awarded for Outstanding Contribution to Music at the NME -New Musical Express- Awards. In June 2013, she was awarded an MBE-Most Excellent Order of the British Empire-for services to music and became a female knight dame.

\section{Album Covers as a Graphic Design Product}

As a graphic design product album covers are the packages of music. These packages both protect and visualize musical expression. The genre of music and the expression of the musicians show itself on these covers by using visuals and typographic combinations which are the elements of graphic design. On these album covers forms fallow functions.

With the new technologies, new forms of recording mediums invented.

\footnotetext{
${ }^{1}$ See Lidwell, W. and Holden, K. ANd Butler, J., Universal Principles of Design (China: Rockport Publishers, Inc. 2003).
} 
On the turning points to new millennium a new version of vinyl records analog sound storage medium-invented as CD audio (compact disc) - digital optical disc data storage - and developed for data storage of different types. With higher capability in smaller size $12 \mathrm{~cm}$ diameter and again circular shape it is called compact disc. Industrial design world created a few ergonomic and regular shaped packages for these CDs; a square for music and movies, a circle for rewritable and a novel like rectangle for movies.

In order to access the data easily there is an accepted organization. Every time there is a booklet in front, pictures and lyrics in and the name of the performer and the album name only on and the two sides. At the back there is a list of the songs/compositions and other details like recording company name, logo, barcode ... etc. In this research, only the 11 to $12 \mathrm{~cm}$ front covers of the booklets are analyzing because all sides designed in unity and it is the main and the most important part.

\section{A. Analysis of Pj Harvey Album Covers}

1. Dry (1992)

Source: Author's Collection.

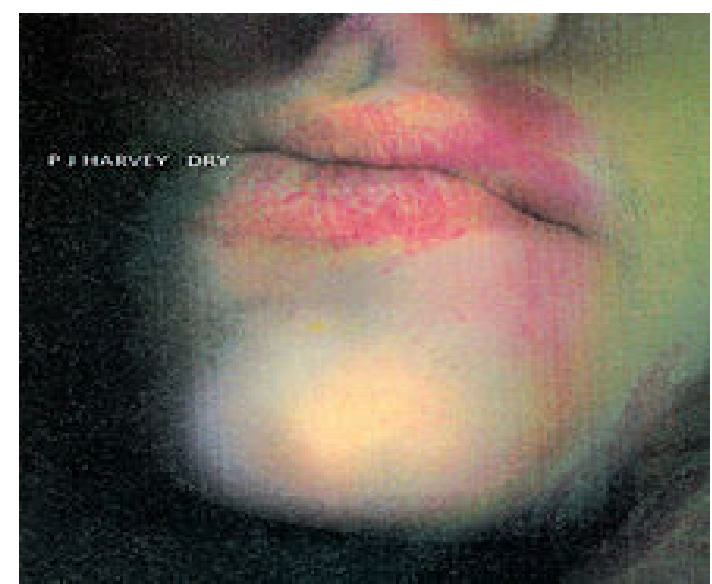

Figure 1 Dry Album Cover

On an album cover there are two verbal; the name of the performer/s and the name of the album. Typography is the art, design and technique of writing. 1992 released Pj Harvey album cover Dry has two verbal "Dry" as the name of the album and "Pj Harvey" as the name of the musician. These words written as small as can be red on the darkest ground as white figures. They are contrasting the most as size and color. A blurred and unusual cropped photograph has been chosen. It takes all the attraction because its 


\section{THE FORMAL AND CONTEXTUAL RELATION 753}

size and blurriness. The viewer thought that he/she is unexpectedly close to the musician. When the viewer divide the surface into two halves downwards can find out that the two halves are balanced asymmetrically by using full and empty spaces. While on the right hand side it is seen a part of a face in huge scale, on the left had side it is seen a small size writing on a black space aligned to the mouth like a speech bubble announcing that "she" is the singer itself. Words are dividing the surface in two horizontally at the golden section of "the" rectangle. All the colors seen are in between the boundaries of the two contrast red and green, and neutrals like grey, black and white. As a typographic element a very plain and simple sans serif modern font has been chosen again contrasting with the curved and blurred outlines of the facial planes. The areal proportions of the face and the black space around have also $1 / 3$ proportion which again attractive inequality.

2. Rid of Me (1993)

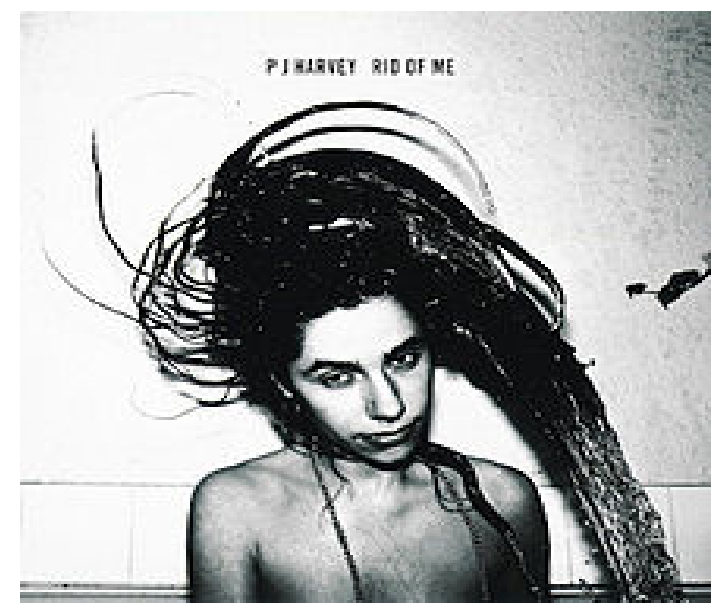

Figure 2 Rid of Me Album Cover.

Source: Author's Collection

1993 released album "Rid of Me" has a black and white color which is neutral colors harmony. The typographic elements are small as they can in order to contrast with the visual. An odd portrait of Harvey naked in front of a textured wall. Human skin texture and material is contrasting with the wall grey contrasting with the wall grain behind. Very light wall grey contrasting with the black letters too. Flying hairs of Harvey disbalance the symmetric setup of the portrait on the plain wall. Only light grey tiles and their edges calm the movement and make the scene organized. Again there is huge proportion contrast and again it is the golden ratio. Unequal and very contrast to take attraction. 


\section{To Bring You My Love (1995)}

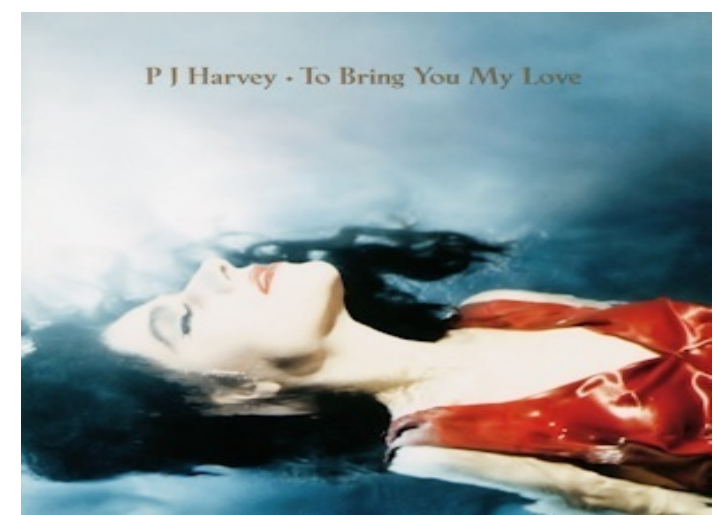

Source: Author's Collection.

Figure 3 To Bring You My Love Album Cover.

1995 released album "To Bring You My Love" cover photograph has two contrasting colors turquoise and bright red to form a contrasting color harmony. To emphasize the woman figure only, she has the bright red on as a dress in flames and as a lipstick on her lips. A floating figure on turquoise water is the theme. This time the asymmetrical balance established with the red dress and black floating hair as strong as the red dress. Because this time a graceful young woman is seen a graceful font for the name of the album and the musician has been chosen. To make the figure and the scene glorious the smallest size has the typography. The visual features of the font and the figure are similar as curves and proportion. Lying figure balanced with a blurred air effect on the upper part of the rectangle and the dark grey typography.

4. Is This Desire? (1998)

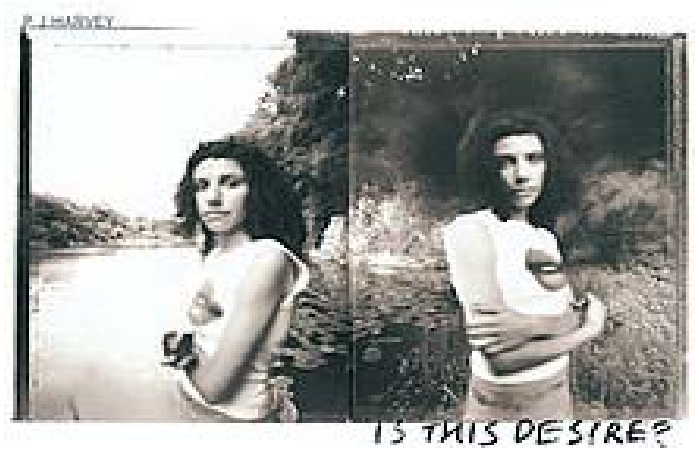

Figure 4 Is This Desire? Album Cover. 


\section{THE FORMAL AND CONTEXTUAL RELATION 755}

1998 released album "Is This Desire?" has a black and white color scheme which is a neutral harmony. The typography is making a contrast with the rest of the surface in size, color and position. But this time the two names of the musician and album separated in size and position. On the black and white photo a double effect irritates the viewer. The symmetrical balance formed full and empty spaces. And has a tonal richness with million tones of grey. The doubleness of the figure makes the scenery timeless and dynamic at the same time. While again the name of the musician still small and plain. The name of the album is bigger, fast, loud and written by directly. The figure is communicating with the viewer. Because the eye scans the rectangle from top left corner and after scanning line by line like reading leaves the surface from bottom right. Placing the typographic elements at these two places isn't accidental. Eyes also fallow the skinny arms and perceive a movement and a dynamic feeling because of changing point of views.

5. Stories from the City, Stories from the Sea (2000)

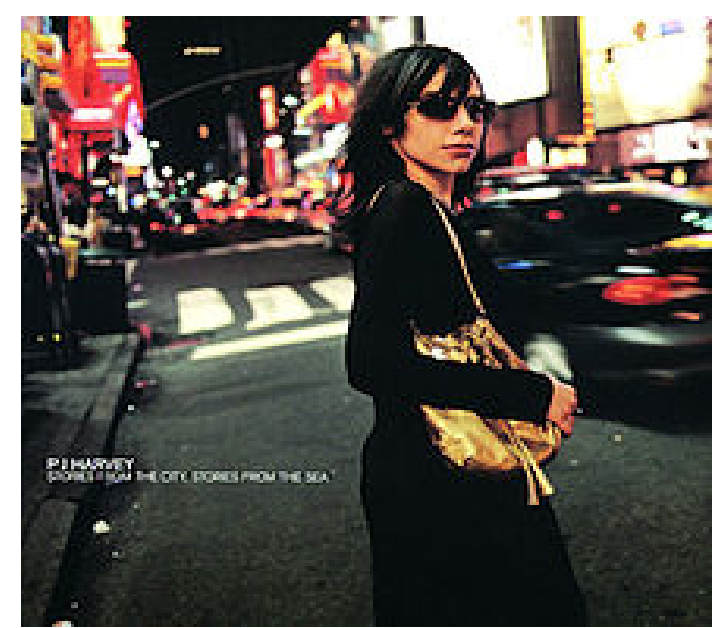

Figure 5 Stories from the City, Stories from the Sea Album Cover. Source: Author's Collection.

2000 released album "Stories from the City, Stories from the Sea" has bright colors balanced with wide black areas. On a city scape's darkest spaces positioned typography as small in size. Because of the size it should have the highest contrasting tone which is white. A plain modern font has chosen. Dynamic effect has the photo and the framing of a behind looking figure in between a fast walk in a big city. 


\section{Uh Huh Her (2004)}

2004 released studio album Uh Huh Her's cover has only neutrals as colors contrasting with black areas. Positive and negative areas divides surface into areas. Viewer failed to understand which is front which is back. Size contrasts, tonal contrasts and the free style typography makes the cover as dynamic as it can be. The handwriting and hand drawing letters are floating on a dark space and differ the musician and the name of the album. On every cover there are references to the musicians self and the world inside her.

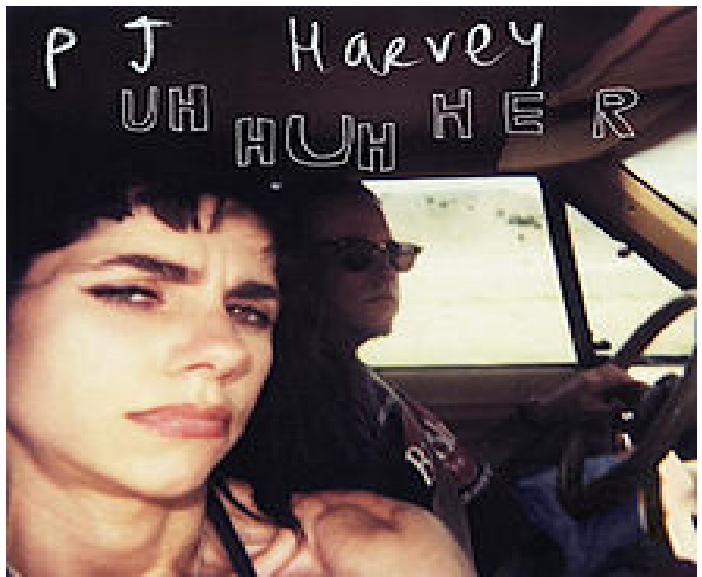

Figure 6 Uh Huh Her Album Cover.

Source: Author's Collection.

7. White Chalk (2007)

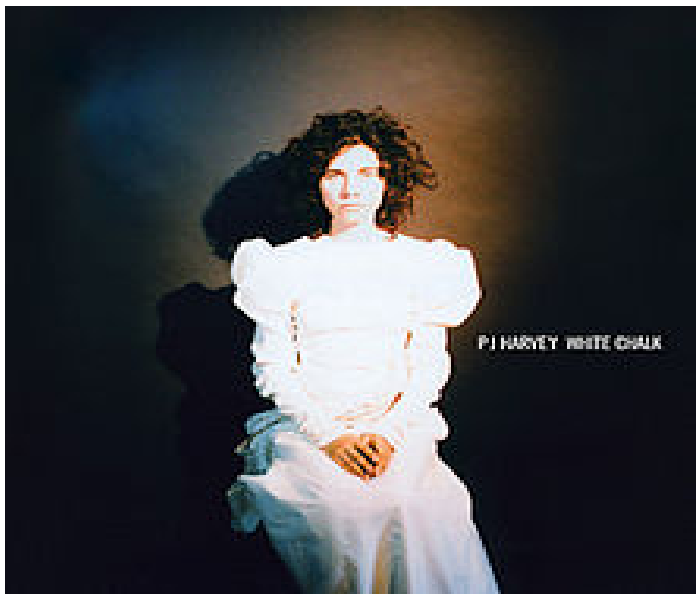

Figure 7 White Chalk Album Cover.

Source: Author's Collection. 


\section{THE FORMAL AND CONTEXTUAL RELATION 757}

2007 released studio album "White Chalk" has its romantic and timeless style on the white dressed $\mathrm{Pj}$ on its cover sitting directly and calm. Neutral color harmony is has. The semi angled light and slight shadow again asymmetrically balanced with the typographic elements. Forming a unity as color the dressed figure and typography contrasting with the dark ground and by their sizes. Plain modern font suites the plain ground and contrasting curly hair and flounces of the dress.

8. Let England Shake (2011)

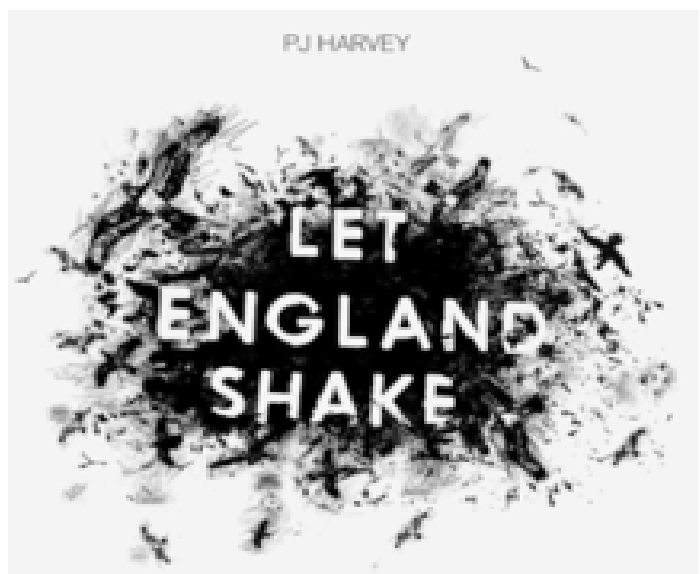

Source: Author's Collection.

Figure 8 Let England Shake Album Cover.

2011 released studio album "Let England Shake" has a very contrasting design attitude by letting out the $\mathrm{Pj}$ figure. Has only two tonesblack and white it is still contrasting on a white space black birds making a black fog. By putting the white typography on this black fog turned this into a black hole deepens into far away. A huge size contrast between the name of the musician and its position makes the illustration leading role. A very plain font makes contrast with the birds and the tone and the thickness makes it readable.

\section{CONCLUSION}

On Pj Harvey's album covers, it is determined that every six of these principles were considered by the graphic designer during the design process as outlined. 